\title{
Green Compressed Fluid Technologies To Extract Antioxidants and Lipids from Galdieria phlegrea in a Biorefinery Approach
}

\author{
Paola Imbimbo, Monica Bueno, Luigi D’Elia, Antonino Pollio, Elena Ibañez, Giuseppe Olivieri,* \\ and Daria Maria Monti*
}

Cite This: ACS Sustainable Chem. Eng. 2020, 8, 2939-2947

Read Online

\section{ACCESS | Lill Metrics \& More | 回 Article Recommendations ｜（） Supporting Information} ABSTRACT: A green cascade approach was used to recover phycocyanins, Wet biomass carotenoids and lipids from Galdiera phlegrea. Phycocyanin extraction was performed by high pressure homogenization and purified by ultrafiltration, whereas carotenoids were obtained by a pressurized liquid extraction and lipids by supercritical fluid extraction. The second step of this innovative, green, and cost-effective procedure is able to improve the recovery of zeaxanthin and $\beta$-carotene up to $40 \%$, without affecting the quality of compounds and avoiding the use of organic solvents and the drying processes. The isolated carotenoids were active as antioxidants, as clearly

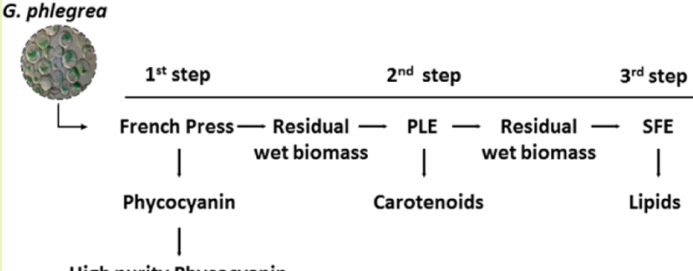
shown by their protective activity on a cell-based model. The lipid yield was increased by $12 \%$ with respect to conventional methods. KEYWORDS: phycocyanin, carotenoids, lipids, compressed fluid technologies, biorefinery, microalgae, Galdieria phlegrea

\section{INTRODUCTION}

Microalgae are a continuous and reliable source of safe natural and high-value products, such as soluble proteins, polyunsaturated fatty acids, and pigments. Phycocyanins (PCs) are blue colored, highly fluorescent, and water-soluble proteins, synthetized in cyanobacteria and red algae. PCs, as the other phycobiliproteins, are antenna pigments that can improve the photosynthetic efficiency of microalgae. Because of their brilliant color, PCs are commonly used in cosmetic and food industry. ${ }^{1}$ They are also endowed with therapeutic properties such as antioxidant, anti-inflammatory, hepato-protective, and antitumoral activity. ${ }^{2}$ Among pigments, carotenoids function as accessory pigments in a light-harvesting photosystem during photosynthesis, $^{3}$ and they are also important for their antioxidant function, as they deactivate free radicals, thus preventing cell damages. In the last decades, carotenoids have attracted great interest because of their beneficial effect on human health. The demand of carotenoids is rapidly growing: the global carotenoid market was estimated to be $\sim 1.24$ billion USD in 2016 and is projected to increase to $\sim 1.53$ billion USD by 2021 , at a compound annual growth rate of $3.78 \%$ from 2016 to 2021 . $^{4}$ To date, commercially available carotenoids are generally synthetic because they are more stable than natural ones as they are formulated to minimize oxidation or isomerization. ${ }^{5}$ However, the emulsified preparations of synthetic carotenoids show high toxicity, carcinogenicity, and teratogenicity properties, thus generating criticism among health-conscious consumers. ${ }^{5,6}$ With microalgae being good producers of many pigments, the extraction of carotenoids from these microorganisms would be very competitive in the market and would have a huge economic impact. ${ }^{7}$ Microalgae can accumulate also significant amount of lipids (from 1 to $70 \%),{ }^{8}$ depending on the strain and the culture conditions. ${ }^{9}$ Lipids can be employed as feedstock for nutraceutical, pharmaceutical, foods, and biofuel industries. To date, the bioenergy market has the lowest value. This is due to the fact that biogas, bioethanol, and biodiesel have a selling price of 0.2 $€ \mathrm{~m}^{-3}, 0.4 € \mathrm{~kg}^{-1}$, and $0.5 € \mathrm{~L}^{-1}$ respectively, a price that still exceeds their high downstream process costs $\left(20.5 € \mathrm{~m}^{-3}\right.$, $33.34 € \mathrm{~kg}^{-1}$, and $25.56 \mathrm{~g} € \mathrm{~L}^{-1}$, respectively). ${ }^{10}$ Thus, an improvement in efficient, cost-effective, and green extraction techniques to produce high-quality compounds is needed. In this context, microalgae are an excellent source of molecules endowed with biological activity. Notably, the design of a suitable integrated biorefinery platform can efficiently extract target compounds in a cascade approach and, in accordance with the green chemistry principles, is still a challenge. Among all the innovative techniques, compressed fluid extractions are considered the most competitive ones because they may fulfill this criteria. ${ }^{11}$ In this context, pressurized liquid extraction (PLE) and supercritical fluid extraction (SFE) are the most widely employed as they could be based on the use of the same system; so they would represent process intensification. PLE and SFE are innovative techniques that use pressurized solvents at an elevated temperature and pressure to extract molecules. Moreover, the extraction performance is enhanced

Received: December 16, 2019

Revised: January 27, 2020

Published: January 31, 2020 
as compared to those techniques carried out at near room temperature and atmospheric pressure. ${ }^{11-13}$

In the present work, we set up a cascade approach to recover high value bioproducts from Galdieria phlegrea, a unicellular thermo-acidophilic red alga. The experimental strategy is reported in Figure 1. Starting from the previously established

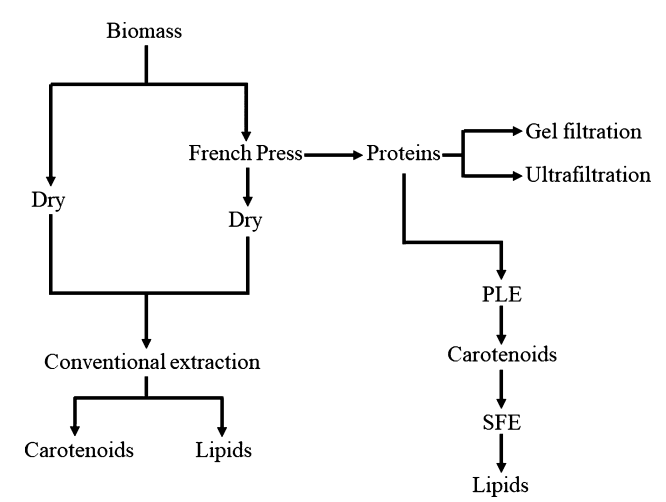

Figure 1. Schematic representation of the extraction strategy.

technique used to disrupt cells and extract PCs, ${ }^{14}$ an optimization of the isolation of PC was carried out. Then, the residual wet biomass was used to extract two different bioproducts in two sequential steps: carotenoids by using PLE and finally lipids by SFE. The bioactivity of the extracted carotenoids obtained by PLE was validated on a cell-based model, using human immortalized keratinocytes and compared to the bioactivity of the commercial molecules.

\section{MATERIALS AND METHODS}

Reagents. High performance liquid chromatography (HPLC)grade acetone and methanol were from VWR (Barcelona, Spain). Antibodies were from Cell Signal Technology (Danvers, MA, USA). All the other reagents and standards were from Sigma-Aldrich (Madrid, Spain).

Microalgal Strain and Culture Conditions. G. phlegrea (strain 009) was provided from the Algal Collection of the University Federico II (ACUF, http://www.acuf.net). Cells were grown in autotrophic conditions in photobioreactors, as described in Imbimbo et al. ${ }^{14}$

PC Extraction and Purification. After harvesting the biomass by centrifugation at $1200 \mathrm{~g}$ for $30 \mathrm{~min}$ at room temperature, cells were suspended in $50 \mathrm{mM}$ sodium acetate $\mathrm{pH}$ 5.5. ${ }^{15}$ Cell disruption was performed by high-pressure (French Press). Two consecutive cycles, each at $2 \mathrm{kbar}$, were performed to disrupt the biomass. The cell lysate was obtained by centrifugation at $5000 \mathrm{~g}$ at $4{ }^{\circ} \mathrm{C}$ for $30 \mathrm{~min}$, and proteins were recovered in the supernatant, whereas the residual biomass was used for further extractions. To purify PC, two single step purification techniques were used in parallel: gel-filtration and ultrafiltration.

The size-exclusion chromatography was performed by using a Sephadex G-75 fine equilibrated in $50 \mathrm{mM}$ sodium acetate $\mathrm{pH}$ 5.5. The ultrafiltration was performed by using $100 \mathrm{kDa}$ molecular weight cut off membranes, and the process was performed at room temperature. At the end of the purification, the permeate was discarded and the retentate was collected. The grade of purity of PC was calculated by measuring the ratio $A_{620 \mathrm{~nm}} / A_{280 \mathrm{~nm}}$.

Storage of Biomass. The residual wet biomass, after protein extraction, was stored at $-80^{\circ} \mathrm{C}$. To avoid that the storage conditions would affect the results, extraction of carotenoids was performed after $72 \mathrm{~h}$.

Conventional Carotenoid Extraction. Carotenoids were extracted using the method of Reyes et al. ${ }^{16}$ Briefly, $200 \mathrm{mg}$ of lyophilized biomass was mixed with $20 \mathrm{~mL}$ of HPLC-grade acetone containing $0.1 \%(\mathrm{w} / \mathrm{v})$ butylate hydroxytoluene, and the mixture was shaken for $24 \mathrm{~h}$ in a thermostatic shaker at $500 \mathrm{rpm}$ and $20^{\circ} \mathrm{C}$. Then, the sample was centrifuged at $4{ }^{\circ} \mathrm{C}$ for $10 \mathrm{~min}$ at $5000 \mathrm{~g}$. The supernatant was collected, and the solvent was removed under $\mathrm{N}_{2}$ stream. The extracts were weighted and stored in the dark at $-20{ }^{\circ} \mathrm{C}$.

Conventional Lipid Extraction. Total lipid extraction was performed according to the Axelsson and Gentili method. ${ }^{17}$ Freezedried microalgae biomass $(25 \mathrm{mg})$ was mixed with $8 \mathrm{~mL}$ of chloroform/methanol 2:1 (v/v). Then, $2 \mathrm{~mL}$ of $\mathrm{NaCl} 0.73 \%(\mathrm{w} / \mathrm{v})$ was added and mixed again. The sample was centrifuged at $350 \mathrm{~g}$ for 5 min at room temperature, allowing the separation of the two phases. The lower layer was removed and collected. The solvent was removed under $\mathrm{N}_{2}$ stream. The extracts were weighted and stored in the dark at $-20{ }^{\circ} \mathrm{C}$.

Compressed Fluid Extraction Processes. All high pressure extractions were performed in a homemade compressed fluid extractor coupled to a PU-2080 HPLC pump from Jasco (Tokyo, Japan). This equipment can be employed to carry out both PLE and SFE. To this purpose, $2 \mathrm{~g}$ of wet algal biomass (the equivalent of 200 $\mathrm{mg}$ of dried biomass) were mixed with silica gel of $150 \AA$ (S150) pore size with a particle size of $200-425$ mesh. The required amount of this silica gel was added as an adsorbent till a static paste was obtained. ${ }^{18}$ Silica prevents the paste draining in the equipment pipeline when loading in the extraction cell and improves the solute recovery. ${ }^{18}$ The mixture was added into a stainless-steel extraction cell sandwiched between glass wool to prevent clogging problems. Extractions were carried out in triplicate in two sequential steps, decreasing the polarity of the solvents, in order to exhaust the microalgae biomass of relevant extractable compounds. PLE was performed at a static extraction mode at $100 \mathrm{bar}, 50{ }^{\circ} \mathrm{C}$ for $30 \mathrm{~min}$ using pure ethanol as a solvent. The extracts were collected in glass vials, dried under $\mathrm{N}_{2}$ stream, and then weighed and stored at $-20{ }^{\circ} \mathrm{C}$ in the dark. Subsequently, the residue of the previous extraction was used as a raw material for the next step. SFE was carried out in the same apparatus, using pure $\mathrm{CO}_{2}$ as a solvent. The extraction was performed at $350 \mathrm{bar}, 60^{\circ} \mathrm{C}$ for $100 \mathrm{~min}$. The $\mathrm{CO}_{2}$ flow rate was set up at $5 \mathrm{~mL} / \mathrm{min}$. Pressure was controlled by using a back pressure regulator. The extracts were collected in glass vials, dried under $\mathrm{N}_{2}$ stream, and then weighed and stored at $-20{ }^{\circ} \mathrm{C}$ in the dark. A schematic representation of the used apparatus is reported in Figure S1 (Supporting Information).

Total Carotenoid Determination. The total carotenoid content was determined spectrophotometrically as described by Gilbert-López et al. ${ }^{19}$ The extracts from PLE were dissolved in pure methanol in a concentration ranging from 0.05 to $5 \mathrm{mg} / \mathrm{mL}$. A standard calibration curve of $\beta$-carotene (from 5 to $200 \mu \mathrm{g} / \mathrm{mL}$ ) was used to calculate the concentration of total carotenoids. The absorbance of samples was recorded at $470 \mathrm{~nm}$. The total carotenoid content was expressed as the ratio of $\mathrm{mg}$ of carotenoids and $\mathrm{g}$ of the extract. The carotenoid yield was expressed as $\mathrm{mg}$ of carotenoids extracted per $\mathrm{g}$ of dry biomass. Analyses was carried out in triplicate.

Carotenoid Characterization by HPLC-DAD-MS. Carotenoids were characterized by HPLC-DAD using the method described by Castro-Puyana et al., ${ }^{20}$ with some modifications. HPLC analyses were performed using an Agilent 1100 series liquid chromatograph (Santa Clara, CA, USA) equipped with a diode-array detector and using a YMC- $\mathrm{C}_{30}$ reversed-phase column $(250 \mathrm{~mm} \times 4.6$ $\mathrm{mm}$ inner diameter, $5 \mu \mathrm{m}$ particle size; YMC Europe, Schermbeck, Germany) and a precolumn YMC- $\mathrm{C}_{30}(10 \mathrm{~mm} \times 4 \mathrm{~mm}$ i.d., $5 \mu \mathrm{m})$. The mobile phase was a mixture of methanol-MTBE-water (90:7:3, $\mathrm{v} / \mathrm{v} / \mathrm{v})$ (solvent A) and methanol-MTBE (10:90, v/v) (solvent B). Carotenoids were eluted according to the following gradient: $0 \mathrm{~min}$, 0\% B; $20 \mathrm{~min}, 30 \%$ B; $35 \mathrm{~min}, 50 \%$ B; $45 \mathrm{~min}, 80 \%$ B; $50 \mathrm{~min}, 100 \%$ B; $60 \mathrm{~min}, 100 \% \mathrm{~B}$; $62 \mathrm{~min}, 0 \% \mathrm{~B}$. The flow rate was $0.8 \mathrm{~mL} / \mathrm{min}$ while the injection volume was $10 \mu \mathrm{L}$. The detection was performed at 280,450 , and $660 \mathrm{~nm}$, although the spectra from 240 to $770 \mathrm{~nm}$ were recorded using the DAD (peak width $>0.1 \mathrm{~min}(2 \mathrm{~s})$ and slit 4 $\mathrm{nm}$ ). The instrument was controlled by LC Chem Station 3D Software Rev. B.04.03 from Agilent. Extracts were dissolved in pure methanol in a concentration ranging from 1 to $10 \mathrm{mg} / \mathrm{mL}$ to 10 and 
Table 1. Comparison in PC Recovery after Gel Filtration and Ultrafiltration ${ }^{a}$

$\begin{array}{lcccc}\text { technique used } & \text { initial PC }\left(\mathrm{mg} / \mathrm{g}_{\text {biomass }}\right) & \text { PC recovery }(\%) & \text { PC concentration }(\mathrm{mg} / \mathrm{mL}) & \text { purity grade }\left(\mathrm{Abs}_{620} / \mathrm{Abs}_{280}\right) \\ \text { gel-filtration } & 98 \pm 1.4 & 78 \pm 8 & 0.19 \pm 0.01 & 5 \pm 0.2 \\ \text { ultrafiltration } & 98 \pm 1.4 & 80 \pm 7 & 13 \pm 1.4^{b} & 5 \pm 1\end{array}$

${ }^{a} \mathrm{PC}$ was determined spectrophotometrically. Data shown are means \pm S.D. of three independent experiments. ${ }^{b} p<0.05$ with respect to gel filtration.

Table 2. Comparison between Conventional Extraction Performed on Raw Biomass and Biomass Post French Press Extraction and PLE Extraction after French Press in Terms of Extracted Carotenoids ${ }^{a}$

\begin{tabular}{|c|c|c|c|c|}
\hline sample & carotenoid yield $\left(\mathrm{mg} / \mathrm{g}_{\text {biomass }}\right)$ & carotenoid content $\left(\mathrm{mg} / \mathrm{g}_{\text {extract }}\right)$ & $\begin{array}{c}\text { zeaxanthin } \\
\left(\mathrm{mg} / \mathrm{g}_{\text {extract }}\right)\end{array}$ & $\begin{array}{c}\beta \text {-carotene } \\
\left(\mathrm{mg} / \mathrm{g}_{\text {extract }}\right)\end{array}$ \\
\hline raw biomass & $62 \pm 2$ & $222 \pm 24$ & $2.7 \pm 0.3$ & $22 \pm 4$ \\
\hline post French press (conventional extraction) & $100 \pm 5^{b}$ & $362 \pm 24^{b}$ & $33.4 \pm 3.7^{b}$ & $320 \pm 76^{b}$ \\
\hline post French press (PLE) & $89 \pm 6$ & $911 \pm 23^{b, c}$ & $48 \pm 5^{b, d}$ & $436 \pm 60^{e}$ \\
\hline
\end{tabular}

${ }^{a}$ Data shown are means \pm S.D. of three independent experiments. ${ }^{b} p<0.05$ with respect to raw biomass. ${ }^{c} p<0.005$ with respect to conventional extraction after PC recovery. ${ }_{p} p<0.05$ with respect to conventional extraction after PC recovery. ${ }^{e} p<0.005$ with respect to raw biomass.

filtered through $0.45 \mu \mathrm{m}$ nylon filters before HPLC analysis. Each dilution was injected in triplicate. For calibration plots, different concentrations of zeaxanthin (from 3.9 to $62.5 \mu \mathrm{g} / \mathrm{mL}$ ) and of $\beta$ carotene (from 31.3 to $1000 \mu \mathrm{g} / \mathrm{mL}$ ) were analyzed in duplicate as described in Gallego et al. ${ }^{21}$ The same instrument was directly coupled at the exit of the DAD to an Agilent ion trap 6320 mass spectrometer (Agilent Technologies) via an atmospheric pressure chemical ionization interface. Analyses were conducted under the positive ionization mode using the parameters described elsewhere. ${ }^{21}$ This time extracts were dissolved in pure methanol in concentrations between 10 and $20 \mathrm{mg} / \mathrm{mL}$ and injected in duplicate. Automatic tandem mass spectrometry (MS/MS) analyses were also performed fragmenting the two highest precursor ions.

ABTS Assay. The antioxidant activity of the lipophilic extract was evaluated by ABTS assay (2,2'-azinobis-[3-ethylbenzthiazoline-6sulfonic acid]). The colorimetric assay is based on the reduction of the $\mathrm{ABTS}^{+}$radical by the antioxidant molecules present in the sample. The radical is produced by the reaction of a $7 \mathrm{mM}$ ABTS solution mixed with $2.45 \mathrm{mM}$ of potassium persulfate conducted for $16 \mathrm{~h}$ at room temperature in the dark. The mixture is then diluted in deionized water to obtain an absorbance of $0.7 \pm 0.02$ at $734 \mathrm{~nm}$. The lipophilic extract in different concentrations was allowed to react with ABTS for $7 \mathrm{~min}$ in the dark, and the absorbance was measured at 734 $\mathrm{nm}$ again. Trolox (6-hydroxy-2,5,7,8-tetramethylchromane-2-carboxylic acid) was used as a standard to obtain a calibration curve. Each extract was analyzed three times in triplicate.

Cell Culture and Cytotoxicity Assay. Human immortalized keratinocytes $(\mathrm{HaCaT})$ were from Innoprot (Biscay, Spain), whereas immortalized murine fibroblasts (BALB/c 3T3) were from ATCC (Manassas, Virginia). Cells were cultured in $10 \%$ fetal bovine serum in Dulbecco's modified Eagle's medium, in the presence of $1 \%$ antibiotics and $2 \mathrm{mM}$ L-glutamine, in a $5 \% \mathrm{CO}_{2}$ humidified atmosphere at $37{ }^{\circ} \mathrm{C}$. $\mathrm{HaCaT}$ cells were seeded in 96-well plates at a density of $2 \times 10^{3}$ cells/well and BALB/c 3 T 3 at a density of $3 \times$ $10^{3}$ cells/well. Approximately $24 \mathrm{~h}$ after seeding, increasing concentrations of the lipophilic extract (from 10 to $100 \mu \mathrm{g} / \mathrm{mL}$ ) were added to the cells for different lengths of time. At the end of each experimental point, cell viability was measured by the MTT assay, as described by Arciello et al. ${ }^{22}$ Cell survival was expressed as the percentage of viable cells in the presence of the lipophilic extract compared to control cells (represented by the average obtained between untreated cells and cells supplemented with the highest concentration of buffer). Each sample was tested in three independent analyses, each carried out in triplicates.

DCFDA Assay. The antioxidant effect of the lipophilic extract (50 $\mu \mathrm{g} / \mathrm{mL}$ ) was measured by determining the intracellular ROS levels. The protocol used by Del Giudice et al. was followed, ${ }^{23}$ with some modifications. Briefly, $\mathrm{HaCaT}$ cells were exposed for different lengths of time to the extract under test and then irradiated by UVA light for
$10 \mathrm{~min}\left(100 \mathrm{~J} / \mathrm{cm}^{2}\right)$. Fluorescence intensity of the fluorescent probe $\left(2^{\prime}, 7^{\prime}\right.$-dichlorofluorescein, DCF $)$ was measured at an emission wavelength of $525 \mathrm{~nm}$ and an excitation wavelength of $488 \mathrm{~nm}$ using a Perkin-Elmer LS50 spectrofluorimeter (Shelton, CT, USA). Emission spectra were acquired at a scanning speed of $300 \mathrm{~nm} / \mathrm{min}$, with 5 slit width both for excitation and emission. ROS production was expressed as a percentage of DCF fluorescence intensity of the sample under test, compared to the untreated sample. Three independent experiments were carried out, each one with three determinations.

Determination of Lipid Peroxidation Levels. The levels of lipid peroxidation were determined by using the thiobarbituric acid reactive substances (TBARS) assay according to the protocol proposed by Petruk et al. ${ }^{24}$ Briefly, $\mathrm{HaCaT}$ cells were preincubated for 15 and $30 \mathrm{~min}$ with the lipophilic extract and then irradiated by UVA light for $10 \mathrm{~min}\left(100 \mathrm{~J} / \mathrm{cm}^{2}\right)$. Cells were detached by trypsin and centrifuged at $1000 \mathrm{~g}$ for $10 \mathrm{~min}, 5 \times 10^{5}$ cells were resuspended in $0.67 \%$ thiobarbituric acid (TBA), and an equal volume of $20 \%$ trichloroacetic acid was added. Samples were then heated at $95{ }^{\circ} \mathrm{C}$ for $30 \mathrm{~min}$, incubated on ice for $10 \mathrm{~min}$, and centrifuged at $3000 \mathrm{~g}$ for 5 min, at $4{ }^{\circ} \mathrm{C}$. TBA reacts with the oxidative degradation products of lipids in samples, yielding red complexes that absorb at $532 \mathrm{~nm}$. Lipid peroxidation levels were expressed as a percentage of absorbance at $532 \mathrm{~nm}$ of the sample under test, compared to the untreated sample. Three independent experiments were carried out, each one with three determinations.

Western Blot Analysis. HaCaT cells were seeded at a density of $3 \times 10^{5}$ cells $/ \mathrm{cm}^{2}$ in a complete medium for $24 \mathrm{~h}$ and then treated with $50 \mu \mathrm{g} / \mathrm{mL}$ of the lipophilic extract for different lengths of time. To analyze Nrf-2 expression levels, nuclear and cytosolic lysates were prepared as follows. Cells were detached by trypsin and centrifuged at $1000 \mathrm{~g}$ for $10 \mathrm{~min}$. Pellets were resuspended in lysis buffer $(0.5 \%$ Triton X-100 in PBS pH 7.4) containing protease and phosphate inhibitors. After $20 \mathrm{~min}$ incubation on ice, samples were centrifuged at $1200 \mathrm{~g}$ for $5 \mathrm{~min}$ at $4{ }^{\circ} \mathrm{C}$. The supernatants were removed and collected as cytosolic lysates. The residual pellets were washed in the same buffer and resuspended in RIPA buffer $(50 \mathrm{mM}$ Tris- $\mathrm{HCl} \mathrm{pH}$ 7.4, $1 \% \mathrm{NP}-40,0.25 \% \mathrm{Na}$ deoxycholate, $150 \mathrm{mM} \mathrm{NaCl}, 1 \mathrm{mM}$ EDTA) completed with protease and phosphatase inhibitors. After 20 min incubation on ice, vortexing every $5 \mathrm{~min}$, samples were centrifuged at $14,000 \mathrm{~g}$ for $30 \mathrm{~min}$ at $4{ }^{\circ} \mathrm{C}$. The supernatants were collected as nuclear lysates. The concentration of samples was determined by the Bradford assay, and the samples were analyzed by sodium dodecyl sulfate-polyacrylamide gel electrophoresis and western blot analysis. To normalize protein intensity levels, antibodies against $\beta$-actin and $\mathrm{B} 23$ were used. The chemiluminescence detection system was from Bio-Rad (Hercules, CA, USA).

Statistical Analysis. Experimental data results were analyzed by ANOVA, and means were compared by Tukey's HSD (SPSS statics 
Table 3. Pigments Detected in G. phlegrea Extracts

\begin{tabular}{|c|c|c|c|c|c|}
\hline peak & identification & $\mathrm{RT}(\min )$ & $\mathrm{UV}$-vis max, $\mathrm{nm}$ & {$[\mathrm{M}+\mathrm{H}]^{+} m / z$} & MS/MS main fragments detected \\
\hline 1 & carotenoid & 13.706 & 450,475 & 664.3 & $607.5,551.5,495.4$ \\
\hline 2 & hydroxychlorophyll $a$ & 15.062 & 430,663 & 910.1 & $893.0,631.8,614.5$ \\
\hline 3 & chlorophyll-type & 15.696 & 426,665 & 940.7 & $629.4,661.4,907.7,852.7,574.4$ \\
\hline 4 & zeaxanthin $^{a}$ & 17.926 & $428,450,476$ & 569.6 & 551.5 \\
\hline 5 & chlorophyll $a^{a}$ & 19.092 & 432,664 & 894.0 & $615.4,583.3$ \\
\hline 6 & chlorophyll $a^{\prime}$ & 20.523 & 430,665 & 894.1 & 615.6 \\
\hline 7 & carotenoid & 21.453 & 445,471 & & \\
\hline 8 & carotenoid & 24.772 & 450,476 & 584.7 & 564.8 \\
\hline 9 & pheophytin $a$ & 30.425 & 408,666 & 872.1 & $594.0,683.3,535.5$ \\
\hline 10 & pheophytin $a^{\prime}$ & 31.681 & 408,666 & 871.9 & 593.8 \\
\hline 11 & $\beta$-carotene ${ }^{a}$ & 33.685 & 450,475 & 537.7 & \\
\hline 12 & carotenoid & 35.591 & 446,472 & 592.8 & 533.4 \\
\hline
\end{tabular}
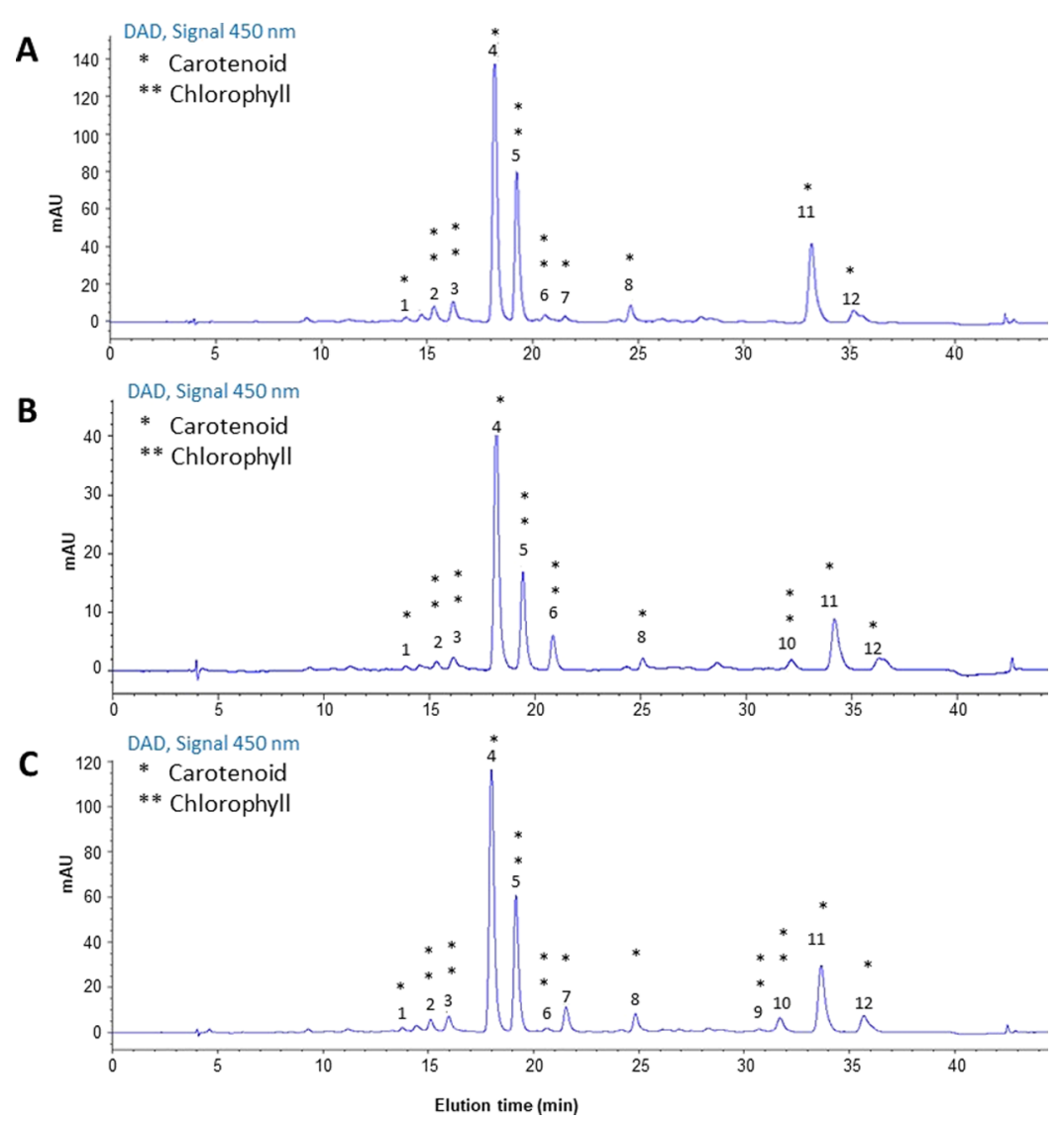

Figure 2. Representative HPLC-DAD chromatograms of carotenoids extracted from G. phlegrea. (A) Conventional extraction of raw biomass; (B) conventional extraction of the residual biomass after PC extraction; (C) PLE extraction of the residual biomass after PC extraction. * indicates carotenoids and $* *$ indicates chlorophylls. Peak numbers and their identification are reported in Table 3.

V15 IBM, New York, United States). The value of $p \leq 0.05$ was considered statistically significant, figured by alphabetical letters along means in tables.

\section{RESULTS AND DISCUSSION}

Optimization of PC Purification. We recently set up a procedure to disrupt $G$. phlegrea biomass by using a conventional high-pressure procedure. PC was then easily recovered from the supernatant by a single purification step, that is, gel filtration. ${ }^{14}$ However, from an economic point of view, the size exclusion chromatography is not feasible, as it is difficult to be scaled-up. Thus, we optimized PC purification by using ultrafiltration and compared the results with those
Table 4. Comparison between Conventional Extractions Performed on Raw Biomass and Biomass Post French Press Extraction and SFE Extraction after French Press in Terms of Extracted Lipids ${ }^{a}$

\begin{tabular}{lc}
\multicolumn{1}{c}{ sample } & lipid yield $\left(\mathrm{mg} / \mathrm{g}_{\text {biomass }}\right)$ \\
raw biomass (conventional extraction) & $110 \pm 3$ \\
post French press (conventional extraction) & $164 \pm 6^{b}$ \\
post French press (SFE) & $184 \pm 5^{b}$
\end{tabular}

${ }^{a}$ Data shown are means \pm S.D. of three independent experiment. ${ }^{b} p<$ 0.05 . 


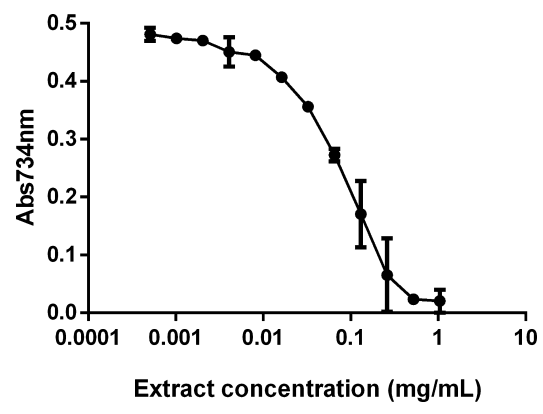

Figure 3. ABTS assay on carotenoids extracted from G. phlegrea. ABTS scavenging activity of different concentrations of the lipophilic extract $(\mathrm{mg} / \mathrm{mL})$ obtained by PLE from G. phlegrea. Data shown are means \pm S.D. of three independent experiments.

previously obtained. As shown in Table 1, both the ultrafiltration technique and gel filtration allow obtaining a PC with a high purity grade. It is known that a purity grade $\leq 0.7$ is indicative of a food grade, between 0.7 and 3.9 is of reagent grade, and $\geq 4.0$ of analytical grade. ${ }^{25}$ As for the yield, about $80 \%$ PC was obtained with both techniques. However, the protein concentration was much higher when ultrafiltration was used, as $13 \mathrm{mg} / \mathrm{mL}$ of PC was obtained with respect to $0.19 \mathrm{mg} / \mathrm{mL}$ of gel filtration.

Total Carotenoid Extraction. Starting from the residual wet biomass after PC extraction, carotenoid extraction was performed by using the PLE technology. In order to compare the carotenoid extraction after PLE, a conventional acetone extraction was performed in parallel on dried raw biomass and on the dried residual biomass after PC extraction, as schematized in Figure 1. Usually, one of the mechanism employed to break cell wall is freeze-drying the biomass, which is a high energy-consuming treatment and causes rapid loss and degradation of carotenoids, thus affecting the bioactivity of the desired compounds. ${ }^{26,27}$ The results of the extractions are reported in Table 2. The carotenoid yield is expressed as mg of carotenoids extracted per g of dry biomass. It is interesting to notice that the conventional extraction allowed obtaining 62 $\mathrm{mg}$ of carotenoids from the raw biomass, whereas about 100 $\mathrm{mg}$ was recovered starting from the disrupted biomass. Thus, a significant increase $(p<0.05)$ in total carotenoid extraction was observed when the disrupted biomass was used. When PLE was employed on residual wet biomass, about $90 \mathrm{mg}$ of carotenoids was obtained. Noteworthy, although the PLE did not increase the extraction yield with respect to the conventional method, the time needed to obtain carotenoids significantly decreased from $24 \mathrm{~h}$ to $30 \mathrm{~min}$. In addition, no organic solvents were used, thus suggesting that this technology is green and very effective. In terms of total carotenoid content, the high-pressure procedure allowed obtaining a purer extract. In fact, as shown in Table 2, the conventional extraction allowed an increase in the carotenoid content up to $63 \%$ when the disrupted biomass was used instead of the raw one $(p<0.05)$. Surprisingly, PLE allowed a further increase of $250 \%$ in the total carotenoid content when compared to the conventional extraction technique on the disrupted biomass $(p<0.005)$ and $400 \%$ on the raw biomass $(p<0.05)$.

Carotenoid Characterization by HPLC-DAD-MS. Carotenoids obtained by the PLE technique were analyzed by high-performance liquid chromatography coupled to the diode array detector and mass spectrometry detector (HPLC$\mathrm{DAD}-\mathrm{MS}$ ) in order to collect more information about the specific pigments (carotenoids and chlorophylls). When possible, a tentative identification was accomplished by combining the information provided by UV-vis spectra from $\mathrm{DAD},[\mathrm{M}+\mathrm{H}]^{+}$, and $\mathrm{MS} / \mathrm{MS}$ fragmentation patterns from the mass spectrometry detector and bibliographic search (Table 3). Chromatographic profiles shown in Figure 2 revealed that the extract obtained by PLE with ethanol is the one with the highest number of pigments.

Peaks numbers 4, 5, and 11 stood out as the most relevant ones, and they could be tentatively identified as zeaxanthin, chlorophyll $a$, and $\beta$-carotene, respectively. These pigments were also present in the pressurized liquid extracts obtained with ethanol from other microalgae (Neochloris oleoabundans ${ }^{20}$ and Porphyridium cruentum $\left.^{21}\right)$. Protonated ions of these compounds were detected $\left(m / z\right.$ 569.6 $[\mathrm{M}+\mathrm{H}]^{+}$for zeaxanthin, $m / z$ 894.0 $[\mathrm{M}+\mathrm{H}]^{+}$for chlorophyll $a$ and $m / z$ $537.7[\mathrm{M}+\mathrm{H}]^{+}$for $\beta$-carotene), along with fragment ions of zeaxanthin and chlorophyll $a$ produced by the loss of a water molecule $\left(m / z 551.5\left[\mathrm{M}+\mathrm{H}-\mathrm{H}_{2} \mathrm{O}\right]^{+}\right)$or phytyl group $(\mathrm{m} / z$ $\left.615.4\left[\mathrm{M}+\mathrm{H}-\mathrm{C}_{20} \mathrm{H}_{38}\right]^{+}\right)$, respectively. Furthermore, the identification of these three compounds was corroborated by the injection of commercial standards.

Other minor chlorophylls, peaks 2 and 9 were tentatively assigned as hydroxychlorophyll $a^{20}$ and pheophytin $a^{11}$ because of their UV-vis UV and MS/MS spectra, showing the particular loss of a phytyl group. Peaks number 6 and 10 have been tentatively identified as chlorophyll $a^{\prime}$ and

\section{A}

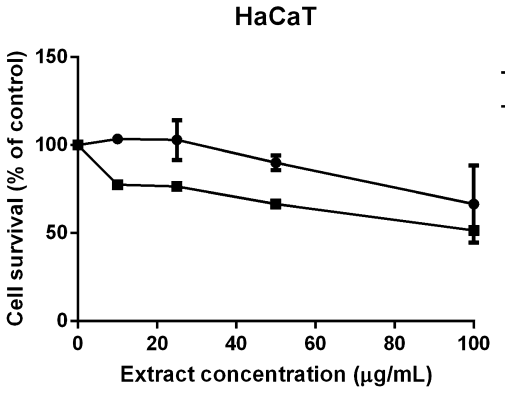

\section{B}

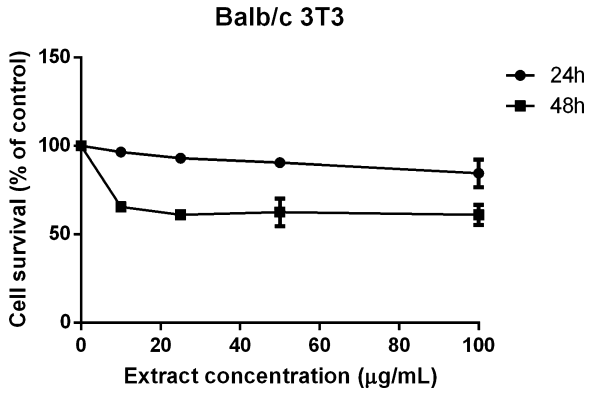

Figure 4. Effect of the lipophilic extract on the viability of $\mathrm{HaCaT}$ and BALB/c $3 \mathrm{~T} 3$ cells. Dose-response curves of HaCaT (A) and BALB/c $3 \mathrm{~T} 3$ (B) cells after $24 \mathrm{~h}$ (black circles) and $48 \mathrm{~h}$ (black squares) incubation with increasing concentrations of lipophilic extracts obtained by PLE (10$100 \mu \mathrm{g} / \mathrm{mL}$ ). Cell viability was assessed by the MTT assay, and cell survival expressed as percentage of viable cells in the presence of the lipophilic extract under test, with respect to control cells grown in the absence of the extract. Data shown are means \pm S.D. of three independent experiments. 
A

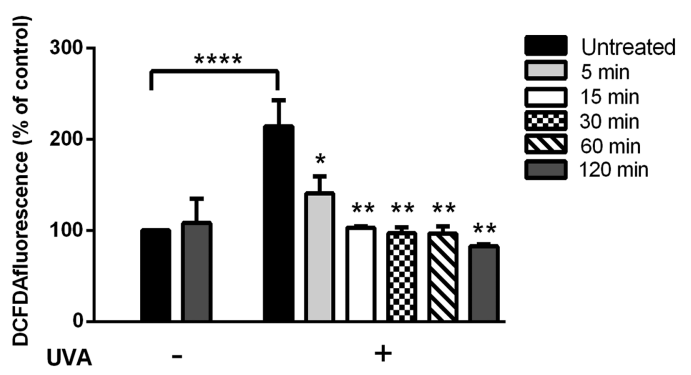

B
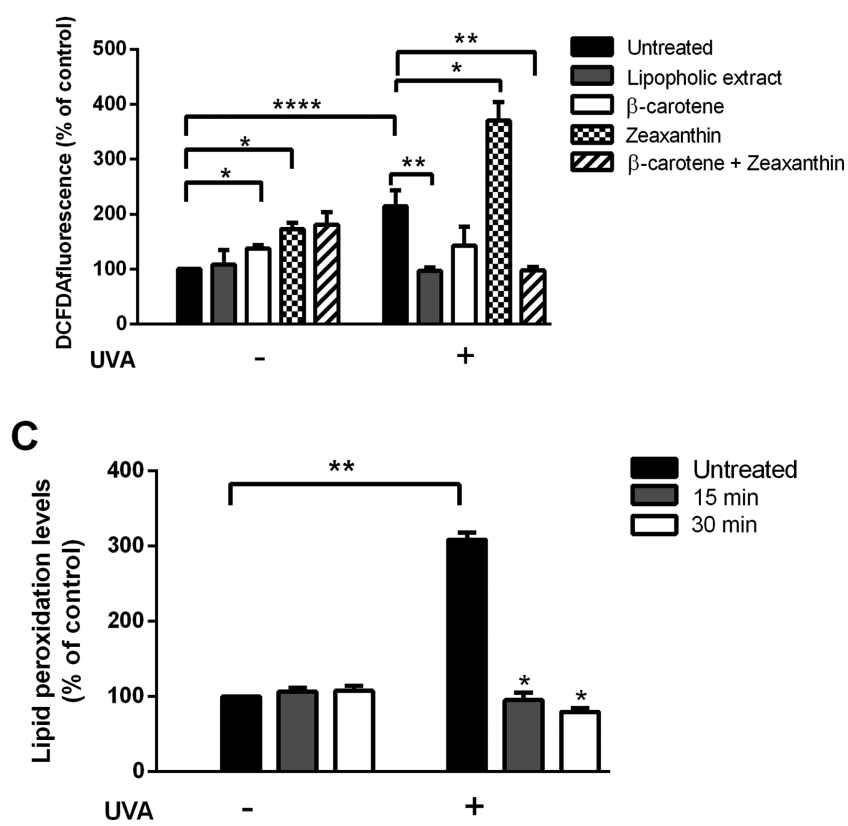

Figure 5. Antioxidant effect of the lipophilic extract from G. phlegrea on stressed $\mathrm{HaCaT}$ cells. Cells were preincubated in the presence of $50 \mu \mathrm{g} / \mathrm{mL}$ lipophilic extract from different lengths of time, prior to be irradiated by UVA $\left(100 \mathrm{~J} / \mathrm{cm}^{2}\right)$. (A) Determination of intracellular ROS levels by DCFDA assay. Cells were incubated for 5 min (light grey bars), $15 \mathrm{~min}$ (white bars), $30 \mathrm{~min}$ (black-squared bars), $60 \mathrm{~min}$ (dashed bars), or $120 \mathrm{~min}$ (dark grey bars) with the lipophilic extract in the absence $(-)$ or in the presence $(+)$ of UVA. Black bars are referred to untreated cells. For each experimental condition, ROS production was measured and a percentage of the ratio between ROS production in treated cells and ROS production in untreated cells was calculated and reported in the graph. (B) Comparison of the protective effect of the lipophilic extract with commercial antioxidants by the DCFDA assay. Cells were incubated for $30 \mathrm{~min}$ prior to UVA exposure. Black bars are referred to untreated cells in the absence (-) or in the presence (+) of UVA. Grey bars are referred to cells incubated with $50 \mu \mathrm{g} / \mathrm{mL}$ lipophilic extract; white bars are referred to cells incubated with $24 \mu \mathrm{g} / \mathrm{mL} \beta$-carotene; black squared bars are referred to cells incubated with $2.4 \mu \mathrm{g} / \mathrm{mL}$ zeaxanthin; and dashed bars are referred to cells incubated with both $\beta$-carotene and zeaxanthin. (C) Analysis of lipid peroxidation levels evaluated by TBARS assay. Cells were preincubated with the lipophilic extract for 15 (grey bars) or $30 \mathrm{~min}$ (white bars) before UVA irradiation. Values are expressed as \% with respect to control (i.e. untreated) cells. For each experimental condition, lipid peroxidation levels were measured, and a percentage of the ratio between lipid peroxidation levels in treated cells and lipid peroxidation levels in untreated cells was calculated and reported in the graph. Data shown are means \pm S.D. of three independent experiment. * indicates $p<0.05$, ** indicates $p<$ 0.005 , and $* * * *$ indicates $p<0.0001$. pheophytin $a^{\prime}$ in concordance with their spectra, similar to those of chlorophyll $a$ and pheophytin $a$ but presenting longer retention times. Peak number 3 presented the characteristic absorbance spectrum of chlorophylls and therefore have been designed as chlorophyll-type.

The rest of the minor peaks in the chromatogram presented the characteristic absorbance spectrum of carotenoids. With the exception of peak number 7 , that could not be detected in MS due to the lack of enough ionization efficiency, the rest of carotenoids were characterized in terms of $[\mathrm{M}+\mathrm{H}]^{+}$, and many fragments from MS/MS were detected. However, a tentative identification was not possible. On the other hand, it is not the first time that peak number 12 has been reported. This carotenoid with the UV-vis spectrum with maximums at 446 and $472 \mathrm{~nm}$ was previously mentioned in gas expanded liquid extracts obtained with $75 \%$ of ethanol from the microalga Scenedesmus obliquus. ${ }^{28}$ In conclusion, the pigment analysis revealed $\beta$-carotene and zeaxanthin as the two main carotenoids in all extracts in agreement with Marquardt, ${ }^{29}$ but with a different Galdieria species (G. sulphuraria).

In addition, a method based on HPLC-DAD was employed to quantify the amount of zeaxanthin and $\beta$-carotene. To fit the calibration curves prepared with the commercial standards of both pigments, the samples analyzed were diluted in pure methanol at different concentrations: $10 \mathrm{mg} / \mathrm{mL}$ for the conventional extraction starting from raw biomass and $1 \mathrm{mg} /$ $\mathrm{mL}$ for the two extracts obtained after French press. Quantification results are reported in Table 2. As expected, PLE improved the amount of both pigments. Moreover, the increase obtained was surprisingly interesting: up to $40 \%$ in comparison with the ones obtained by conventional extraction and to about 2000 times with respect to the raw biomass.

Total Lipid Extraction. To further improve the biorefinery design, after the PLE extraction a lipid extraction was carried out using supercritical $\mathrm{CO}_{2}\left(\mathrm{ScCO}_{2}\right)$. Notably, both PLE and SFE were performed on the same apparatus, without the need to recover the biomass from the extraction cell after carotenoid extraction. In particular, after PLE, $\mathrm{CO}_{2}$ was injected in the extraction cell to push out ethanol-containing carotenoids. Afterward, pressure was increased to the super critical point, and lipids were extracted (Figure S1). As a benchmark, conventional chloroform/methanol extraction was carried out on raw dried biomass and on the residual dried biomass after PC extraction. Results of the extractions are reported in Table 4. The $\mathrm{ScCO}_{2}$ extraction allowed obtaining the same amount of lipids that those by conventional extraction, avoiding the use of an organic solvent. This result was quite surprising, as the lipids extracted are the third class of molecules obtained in a biorefinery approach. When compared with our previous results, ${ }^{14}$ we found a lower recovery in lipid yield, but this could be due to a different extraction method used.

Evaluation of Biocompatibility and Antioxidant Activity of Lipophilic Extract Obtained by PLE Extraction on Eukaryotic Cells. To verify if the carotenoids extracted by the PLE technique were biologically active and safe for humans, their in vitro antioxidant activity, along with their biocompatibility on eukaryotic cells, was tested. The results of the in vitro ABTS colorimetric assay are shown in Figure 3 and clearly indicate that the lipophilic extract is endowed with a significant antioxidant activity. Its $\mathrm{IC}_{50}$ value, that is, the concentration of the extract that can inhibit $50 \%$ of the radical, is $50 \mu \mathrm{g} / \mathrm{mL}$. This result is much lower than those reported in the literature, as the $\mathrm{IC}_{50}$ value here obtained is 

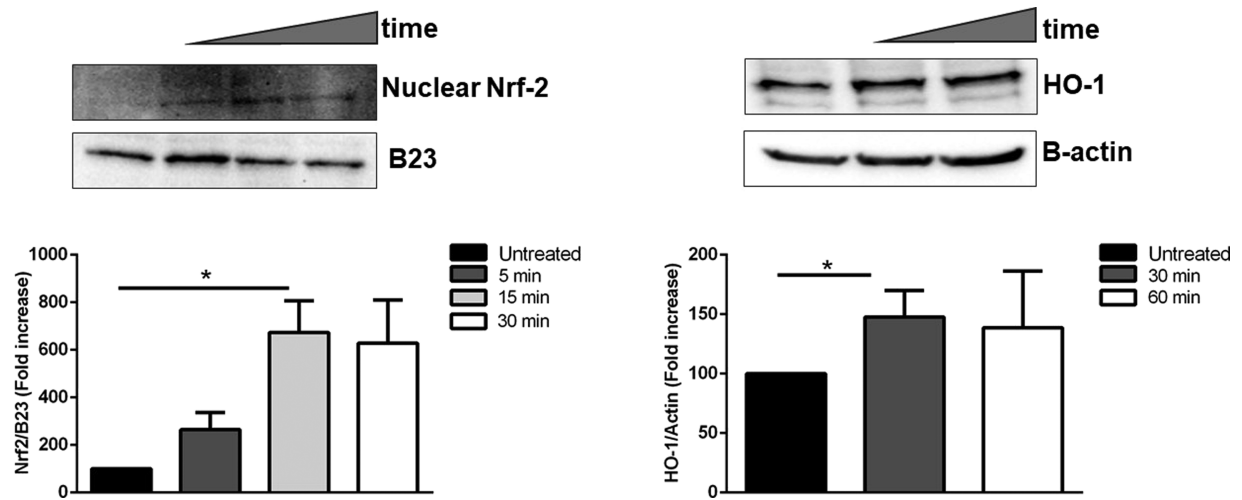

Figure 6. Effect of the lipophilic extract on Nrf-2 activation on HaCaT cells. Cells were incubated with $50 \mu \mathrm{g} / \mathrm{mL}$ lipophilic extract obtained by the PLE technique for different lengths of time and then nuclear (A) or cytosolic (B) proteins were analyzed by western blotting. (A) Western blot analysis of nuclear Nrf-2 after 5 min (dark grey bar), 15 min (light grey bar), and 30 min (white bar) incubation. Nuclear Nrf-2 and B23 were quantified by densitometric analysis. The ratio between Nrf-2 and B23 of each treated sample was then related to the ratio Nrf-2/B23 of untreated cells, considered as $100 \%$. (B) Western blot analysis of cytosolic HO-1 was performed after incubation with $50 \mu \mathrm{g} / \mathrm{mL}$ of the extract for 30 min (dark grey bar) and $60 \mathrm{~min}$ (white bar). HO-1 and $\beta$-actin were quantified by densitometric analysis, and the ratio HO- $1 / \beta$-actin of each treated sample was then related to the ratio HO- $1 / \beta$-actin of untreated cells, considered as $100 \%$. Data shown are means \pm S.D. of three independent experiments. * indicates $p<0.05$ with respect to control cells.

about 1600 times lower than others reported with different microalgae. ${ }^{30}$ The biocompatibility of the extract was tested by a time-course and dose-response test on immortalized murine fibroblasts (BALB/c 3T3) and immortalized human keratinocytes $(\mathrm{HaCaT})$. Cell viability was assessed by the tetrazolium salt colorimetric (MTT) assay, and cell survival was expressed as the percentage of viable cells in the presence of the extract compared to that of control samples. As shown in Figure 4A,B, after $48 \mathrm{~h}$, cell viability was not affected up to $50 \mu \mathrm{g} / \mathrm{mL}$, while at the highest concentration tested $(100 \mu \mathrm{g} / \mathrm{mL})$, a $50 \%$ reduction of cell viability was observed.

Protective Effect of the Lipophilic Extract against Oxidative Stress on HaCaT Cells. As the lipophilic extract obtained by PLE contains antioxidants, the potential protective effect against oxidative stress was analyzed on a cell-based model. As a cell system, we chose immortalized keratinocytes as they are normally present in the outermost layer of the skin and UVA radiations as a source of stress. Cells were treated with $50 \mu \mathrm{g} / \mathrm{mL}$ extracts for different lengths of time (from 5 to $120 \mathrm{~min})$, and then oxidative stress was induced by UVA irradiation $\left(100 \mathrm{~J} / \mathrm{cm}^{2}\right)$. Immediately after irradiation, ROS levels were measured by using $\mathrm{H}_{2} \mathrm{DCF}-\mathrm{DA}$ as a probe. For each set of experiments, untreated cells were used as a control. Under physiological conditions (i.e., in the case of untreated cells), a physiological release of ROS is observed (100\%). As shown in Figure 5A, no effect on ROS levels was observed when cells were incubated with the extract for $120 \mathrm{~min}$ (grey bars), whereas UVA treatment significantly increased DCF fluorescence intensity (black bars). Interestingly, pretreatment of cells with the lipophilic extract, prior to UVA exposure, resulted in an inhibition of ROS production, which was clear already after $5 \mathrm{~min}$ of pretreatment. We then performed a comparison between the antioxidant activity of the total lipophilic extract obtained by PLE and commercial $\beta$-carotene and zeaxanthin, the two most abundant species identified in the extract. On the basis of the quantification data reported in Table 2, we calculated that, when the lipophilic extract was tested at $50 \mu \mathrm{g} / \mathrm{mL}$, the amount of $\beta$-carotene corresponded to $24 \mu \mathrm{g} / \mathrm{mL}$ and that of zeaxanthin to $2.4 \mu \mathrm{g} / \mathrm{mL}$. Thus, $\mathrm{HaCaT}$ cells were preincubated for $30 \mathrm{~min}$ with either: $50 \mu \mathrm{g} / \mathrm{mL}$ of lipophilic extract; $24 \mu \mathrm{g} / \mathrm{mL}$ of $\beta$-carotene; $2.4 \mu \mathrm{g} / \mathrm{mL}$ of zeaxanthin; a mixture of both carotenoids. At the end of incubation, oxidative stress was induced as previously mentioned. Alteration of ROS levels was measured by using $\mathrm{H}_{2}$ DCF-DA. As shown in Figure 5B, a significant increase in ROS production was observed when cells were incubated with commercial $\beta$-carotene (white bars) or zeaxanthin (black squared bars), also in the absence of any UVA exposure. Interestingly, only the mixture of both commercial carotenoids (dashed bars), as well as the lipophilic extract (grey bars), were able to counteract oxidative stress in a similar way. The protective effect of the lipophilic extract was also confirmed by analyzing the lipid peroxidation levels. To this purpose, TBARS were measured and related to lipid peroxidation levels. A significant increase in lipid peroxidation levels was observed after UVA treatment, but, notably, this effect was abolished when cells were pretreated with the lipophilic extract, either after 15 or 30 min preincubation (grey and white bars, respectively). Treatment of cells with the lipophilic extract did not alter significantly lipid peroxidation levels (Figure 5C).

Nrf-2 Regulates the Antioxidant Activity of the Lipophilic Extract. To understand the molecular mechanism responsible for the protective effect of the lipophilic extract, the involvement of the transcription factor $\mathrm{Nrf}-2$ was analyzed. Under normal physiological conditions, Nrf-2 is associated with Keap-1, which retains Nrf-2 in the cytosol and directs it to the proteasomal degradation. Upon either oxidative stress induction and/or in the presence of antioxidants, Keap-1 dissociates from Nrf-2, which is translocated to the nucleus where it binds to antioxidant responsive elements sequences and activates the transcription of several phase-II detoxifying enzymes. ${ }^{31}$ Thus, we incubated HaCaT cells in the presence of the lipophilic extract for different length of time (from 5 to 30 $\mathrm{min}$ ), and lysates were analyzed by western blot analysis, using Nrf-2 antibody. As shown in Figure 6A, an increase in nuclear Nrf- 2 was observed after $15 \mathrm{~min}$ of incubation. The activation of Nrf-2 was further confirmed by analyzing the translation level of the heme oxygenase-1 (HO-1) by western blot analysis. HO-1 is a ubiquitous and redox-sensitive inducible stress protein that degrades heme to $\mathrm{CO}$, iron, and biliverdin. ${ }^{32}$ The importance of this protein in physiological and 
pathological states is underlined by the versatility of $\mathrm{HO}-1$ inducers and the protective effects attributed to heme oxygenase products in conditions that are associated with moderate or severe cellular stress. Thus, $\mathrm{HaCaT}$ cells were incubated for 30 and $60 \mathrm{~min}$, and lysates were analyzed by western blot analysis, using a HO-1 antibody. As shown in Figure 6B, an increase in HO-1 levels was observed after 30 min of incubation.

\section{CONCLUSIONS}

One of the aims of green chemistry is to preserve the natural environment, promoting a better use of resources and limiting the negative influence of human involvement, such as the use of procedures that require the use of toxic solvents. ${ }^{33}$ Compared to conventional extractions, this innovative green biorefinery approach is able to extract, in cascade, three different bioactive compounds from the microalga G. phlegrea. In combination, the described process allows achieving higher yields of PC, carotenoids, and lipids using Generally Recognized As Safe (GRAS) solvents, in shorter time and with less solvent consumption. Here, we demonstrated that PLE using ethanol has a high potential to extract carotenoids from G. phlegrea. Moreover, as G. phlegrea is an eukaryotic microalga, it possesses a robust cell wall, which prevents the release of intracellular products. The idea of breaking the biomass by high pressure homogenization allowed to isolate PC and helped the subsequent release of carotenoids. Both final products, PC, and carotenoids were biologically active in terms of antioxidant activity. ${ }^{14}$ These results will open the way to the idea of commercializing carotenoids from microalgae for cosmeceutical applications. In conclusion, this work will help to achieve a complete valorization of the G. phlegrea microalga biomass. The results can then contribute to increase the revenue streams of the process, in order to compensate the large cultivation and downstream cost for biomass production and, finally, turn positive the economic balance of the microalgae biorefinery. Furthermore, they contribute to develop a green process which can also increase the social acceptance of industrial microalgal products.

\section{ASSOCIATED CONTENT}

\section{SI Supporting Information}

The Supporting Information is available free of charge at https://pubs.acs.org/doi/10.1021/acssuschemeng.9b07505.

Schematic representation of the equipment employed for compressed fluid extractions (PDF)

\section{AUTHOR INFORMATION}

\section{Corresponding Authors}

Giuseppe Olivieri - Bioprocess Engineering Group, Wageningen University and Research, 6700AA Wageningen, The

Netherlands; Department of Chemical, Materials and Industrial Engineering, University of Naples Federico II, 80125 Naples, Italy; Email: giuseppe.olivieri@wur.nl

Daria Maria Monti - Department of Chemical Sciences, University of Naples Federico II, 80126 Naples, Italy; ○ orcid.org/0000-0002-1136-0576; Email: mdmonti@ unina.it

\section{Authors}

Paola Imbimbo - Department of Chemical Sciences, University of Naples Federico II, 80126 Naples, Italy
Monica Bueno - Laboratory of Foodomics, Institute of Food Science Research, CIAL, CSIC, 28049 Madrid, Spain

Luigi D'Elia - Department of Chemical Sciences, University of Naples Federico II, 80126 Naples, Italy

Antonino Pollio - Department of Biology, University of Naples Federico II, 80126 Naples, Italy

Elena Ibañez - Laboratory of Foodomics, Institute of Food Science Research, CIAL, CSIC, 28049 Madrid, Spain

Complete contact information is available at: https://pubs.acs.org/10.1021/acssuschemeng.9b07505

\section{Notes}

The authors declare no competing financial interest.

\section{ACKNOWLEDGMENTS}

M.B. acknowledges MINECO for the "Juan de La CiervaFormación” postdoctoral grant FJCI-2016-30902. This research was financed under projects ABACUS (Algae for a Biomass Applied to the produCtion of added value compounds-funded by the Bio Based Industries Joint Undertaking under the European Union's Horizon 2020 research and innovation programme under grant agreement no. 745668) and AGL2017-89417-R (MINECO, Spain).

\section{REFERENCES}

(1) Santiago-Santos, M. C.; Ponce-Noyola, T.; Olvera-Ramírez, R.; Ortega-López, J.; Cañizares-Villanueva, R. O. Extraction and Purification of Phycocyanin from Calothrix Sp. Process Biochem. 2004, 39, 2047-2052.

(2) Basha, O. M.; Hafez, R. A.; El-Ayouty, Y. M.; Mahrous, K. F.; Bareedy, M. H.; Salama, A. M. C-Phycocyanin Inhibits Cell Proliferation and May Induce Apoptosis in Human HepG2 Cells. Egypt. J. Immunol. 2008, 15, 161-167.

(3) Jin, E. S.; Melis, A. Microalgal Biotechnology: Carotenoid Production by the Green Algae Dunaliella Salina. Biotechnol. Bioprocess Eng. 2003, 8, 331-337.

(4) Sathasivam, R.; Ki, J.-S. A Review of the Biological Activities of Microalgal Carotenoids and Their Potential Use in Healthcare and Cosmetic Industries. Mar. Drugs 2018, 16, 26.

(5) Nagarajan, J.; Ramanan, R. N.; Raghunandan, M. E.; Galanakis, C. M.; Krishnamurthy, N. P. Carotenoids; Elsevier Inc.; Chapter 8, 2017.

(6) Blomhoff, R. Vitamin A and Carotenoid Toxicity. Food Nutr. Bull. Suppl. 2001, 22, 320-334.

(7) Ambati, R. R.; Gogisetty, D.; Aswathanarayana, R. G.; Ravi, S.; Bikkina, P. N.; Bo, L.; Yuepeng, S. Industrial Potential of Carotenoid Pigments from Microalgae: Current Trends and Future Prospects. Crit. Rev. Food Sci. Nutr. 2019, 59, 1880-1902.

(8) Spolaore, P.; Joannis-Cassan, C.; Duran, E.; Isambert, A. Commercial Applications of Microalgae. J. Biosci. Bioeng. 2006, 101, $87-96$.

(9) Pruvost, J.; Van Vooren, G.; Le Gouic, B.; Couzinet-Mossion, A.; Legrand, J. Systematic Investigation of Biomass and Lipid Productivity by Microalgae in Photobioreactors for Biodiesel Application. Bioresour. Technol. 2011, 102, 150-158.

(10) Barsanti, L.; Gualtieri, P. Is Exploitation of Microalgae Economically and Energetically Sustainable? Algal Res. 2018, 31, $107-115$.

(11) Gallego, R.; Bueno, M.; Herrero, M. Sub- and Supercritical Fluid Extraction of Bioactive Compounds from Plants, Food-byProducts, Seaweeds and Microalgae - An Update. TrAC, Trends Anal. Chem. 2019, 116, 198-213.

(12) Camel, V. Recent Extraction Techniques for Solid Matrices Supercritical Fluid Extraction, Pressurized Fluid Extraction and Microwave-Assisted Extraction: Their Potential and Pitfalls. Analyst 2001, 126, 1182-1193. 
(13) Mubarak, M.; Shaija, A.; Suchithra, T. V. A Review on the Extraction of Lipid from Microalgae for Biodiesel Production. Algal Res. 2015, 7, 117-123.

(14) Imbimbo, P.; Romanucci, V.; Pollio, A.; Fontanarosa, C.; Amoresano, A.; Zarrelli, A.; Olivieri, G.; Monti, D. M. A Cascade Extraction of Active Phycocyanin and Fatty Acids from Galdieria Phlegrea. Appl. Microbiol. Biotechnol. 2019, 103, 9455-9464.

(15) Wu, H.-L.; Wang, G.-H.; Xiang, W.-Z.; Li, T.; He, H. Stability and Antioxidant Activity of Food-Grade Phycocyanin Isolated fromSpirulina platensis. Int. J. Food Prop. 2016, 19, 2349-2362.

(16) José, M.; Reyes, F. A.; Mendiola, J. A.; Iba, E. Astaxanthin Extraction from Haematococcus Pluvialis Using CO 2 -Expanded Ethanol. J. Supercrit. Fluids 2014, 92, 75-83.

(17) Axelsson, M.; Gentili, F. A Single-Step Method for Rapid Extraction of Total Lipids from Green Microalgae. PloS One 2014, 9, No. e89643.

(18) Reyes, F. A.; Mendiola, J. A.; Suárez-Alvarez, S.; Ibañez, E.; Del Valle, J. M. Adsorbent-Assisted Supercritical $\mathrm{CO} 2$ Extraction of Carotenoids from Neochloris Oleoabundans Paste. J. Supercrit. Fluids 2016, 112, 7-13.

(19) Gilbert-López, B.; Mendiola, J. A.; Fontecha, J.; Van Den Broek, L. A. M.; Sijtsma, L.; Cifuentes, A.; Herrero, M.; Ibáñez, E. Downstream Processing of Isochrysis Galbana: A Step towards Microalgal Biorefinery. Green Chem. 2015, 17, 4599-4609.

(20) Castro-Puyana, M.; Herrero, M.; Urreta, I.; Mendiola, J. A.; Cifuentes, A.; Ibáñez, E.; Suárez-Alvarez, S. Optimization of Clean Extraction Methods to Isolate Carotenoids from the Microalga Neochloris Oleoabundans and Subsequent Chemical Characterization Using Liquid Chromatography Tandem Mass Spectrometry. Anal. Bioanal. Chem. 2013, 405, 4607-4616.

(21) Gallego, R.; Martínez, M.; Cifuentes, A.; Ibáñez, E.; Herrero, M. Development of a Green Downstream Process for the Valorization of Porphyridium Cruentum Biomass. Molecules 2019, 24, 1564.

(22) Arciello, A.; De Marco, N.; Del Giudice, R.; Guglielmi, F.; Pucci, P.; Relini, A.; Monti, D. M.; Piccoli, R. Insights into the Fate of the N-Terminal Amyloidogenic Polypeptide of ApoA-I in Cultured Target Cells. J. Cell. Mol. Med. 2011, 15, 2652-2663.

(23) Del Giudice, R.; Petruk, G.; Raiola, A.; Barone, A.; Monti, D. M.; Rigano, M. M. Carotenoids in Fresh and Processed Tomato (Solanum Lycopersicum) Fruits Protect Cells from Oxidative Stress Injury. J. Sci. Food Agric. 2017, 97, 1616-1623.

(24) Petruk, G.; Raiola, A.; Del Giudice, R.; Barone, A.; Frusciante, L.; Rigano, M. M.; Monti, D. M. An Ascorbic Acid-Enriched Tomato Genotype to Fight UVA-Induced Oxidative Stress in Normal Human Keratinocytes. J. Photochem. Photobiol., B 2016, 163, 284-289.

(25) Fernández-Rojas, B.; Hernández-Juárez, J.; Pedraza-Chaverri, J. Nutraceutical Properties of Phycocyanin. J. Funct. Foods 2014, 11, 375-392.

(26) Mcmillan, J. R.; Watson, I. A.; Ali, M.; Jaafar, W. Evaluation and Comparison of Algal Cell Disruption Methods: Microwave, Waterbath, Blender, Ultrasonic and Laser Treatment. Appl. Energy 2013, 103, 128-134.

(27) Papaioannou, E.; Roukas, T.; Liakopoulou-Kyriakides, M. Effect of Biomass Pre-Treatment and Solvent Extraction on $\beta$ Carotene and Lycopene Recovery from Blakeslea Trispora Cells. Prep. Biochem. Biotechnol. 2008, 38, 246-256.

(28) Gilbert-López, B.; Mendiola, J. A.; van den Broek, L. A. M.; Houweling-Tan, B.; Sijtsma, L.; Cifuentes, A.; Herrero, M.; Ibáñez, E. Green Compressed Fluid Technologies for Downstream Processing of Scenedesmus Obliquus in a Biorefinery Approach. Algal Res. 2017, 24, 111-121.

(29) Marquardt, J. Effects of Carotenoid-Depletion on the Photosynthetic Apparatus of a Galdieria Sulphuraria (Rhodophyta) Strain That Retains Its Photosynthetic Apparatus in the Dark. J. Plant Physiol. 1998, 152, 372-380.

(30) Peraman, M.; Nachimuthu, S. Identification and Quantification of Fucoxanthin in Selected Carotenoid-Producing Marine Microalgae and Evaluation for Their Chemotherapeutic Potential. Pharmacogn. Mag. 2019, 15, 243-249.
(31) Ma, Q. Role of Nrf2 in Oxidative Stress and Toxicity. Annu. Rev. Pharmacol. Toxicol. 2013, 53, 401.

(32) Balogun, E.; Hoque, M.; Gong, P.; Killeen, E.; Green, C. J.; Foresti, R.; Alam, J.; Motterlini, R. Curcumin Activates the Haem Oxygenase-1 Gene via Regulation of Nrf2 and the AntioxidantResponsive Element. Biochem. J. 2003, 371, 887-895.

(33) Mustafa, A.; Turner, C. Analytica Chimica Acta Pressurized Liquid Extraction as a Green Approach in Food and Herbal Plants Extraction: A Review. Anal. Chim. Acta 2011, 703, 8-18. 